\title{
Importância do manejo no controle da mortalidade de bezerros em uma propriedade rural de exploração mista de bovinos
}

\section{Reduction of calves mortality rate after management changes, in a farm with crossbreed cows herdy}

\author{
Luiz Antônio Franco da Silva, ${ }^{*}$ Cléverson Santos Acypreste, ${ }^{\star *}$ Francisco de Carvalho Dias, ${ }^{*}$ \\ Maria Clorinda Soares Fioravanti, ${ }^{*}$ Ludmila de Souza Ramos, ${ }^{\star \star \star}$ Patrícia Alesi Teixeira ${ }^{\star \star \star \star}$
}

\begin{abstract}
Resumo
Acompanharam-se os índices de mortalidade de bezerros em uma fazenda de exploração mista de bovinos no Estado de Goiás no período compreendido entre1994 e 1997 à medida que eram introduzidas mudanças de manejo. As modificações implantadas visaram melhorar a sobrevivência e a sanidade destes animais, e constaram de formação de piquetes de parição, acompanhamento do parto, corte e desinfecção do umbigo, administração de colostro nas primeiras horas pósnascimento, formação de piquetes e suplementação destinados aos bezerros e treinamento da mão-de-obra auxiliar. A propriedade possui cerca de 1000 ha dividida em dois retiros destinados à bovinocultura, com 650 vacas com graus variáveis de sangue Zebu/Holandês. Ao iniciar o estudo no ano de 1994, fez-se uma avaliação inicial da situação, antecedendo a implantação das mudanças de manejo, onde foi constatado índice de mortalidade de bezerros de 18,65\%. Para os anos subseqüentes a mortalidade decresceu para 9,39\%,6,45\% e 4,67\%. As principais causas de morte em ordem decrescente durante o estudo foram atribuídos às hemoparasitoses $(20,8 \%)$, diarréias $(19,2 \%)$ e desnutrição (12\%). Os demais óbitos foram atribuídos à pneumonia $(11,2 \%)$, onfaloflebite $(8 \%)$, etc. A redução nos índices de mortalidade provavelmente ocorrem em função do conjunto de medidas adotadas, demostrando que as mudanças introduzidas, apesar de simples, reduziram para índices aceitáveis os óbitos em bezerros.
\end{abstract}

Palavras-chave: bezerros; mortalidade; manejo.

\begin{abstract}
This study was made in a farm (Goiás State) with 1000 ha and 650 crossbreed cows. In 1994, the calves mortality rate was $18,65 \%$. The mortality causes were tick fever $(20,80 \%)$, diarrheas $(19,20 \%)$, desnutrition $(12,00 \%)$ pneumonia (11,20\%) and onfaloflebitis $(8,00 \%)$. After to stablish a maternity paddock, delivery attendance, navel desinfection, colostrum administration to newborn calves, food supplementation to the calves and training the workers, the calves mortality rate reduced slowly in the next years. In 1995 this rate was 9,39\%, in 1996 and 1997 haas $6,45 \%$ and 4,67\% respectively. Therefore, it was possible to observe that simple management changes reduced the mortality rate in this farm.
\end{abstract}

Keywords: calves; mortality; management.

\section{Introdução}

Os altos índices de mortalidade observados em bezerros nas propriedades rurais do Brasil central, nas primeiras semanas de vida, limitam a produtividade e, geralmente, resultam em grandes prejuízos para os criatórios. Provavelmente, a nutrição seja um dos fatores que contribuem para que a perda de animais nessa faixa etária seja expressiva. Enfermidades comuns em bezerros recém-nascidos, como as di- arréias, as pneumonias e as onfaloflebites, apesar de freqüentes, são de ocorrência menor em animais bem nutridos, pois a nutrição adequada minimiza a pressão que os microrganismos patogênicos exercem sobre a produção animal, prevenindo doenças que podem levar à morte.

A administração correta do colostro aos recém-nascidos é uma das medidas que podem melhorar a sobrevivência dos bezerros, porém, isoladamente, não é suficiente para resol-

\footnotetext{
* Professores da Escola de Veterinária - Universidade Federal de Goiás - Campus II Samambaia, C. postal 131, CEP. $74001 .-970$ E-mail clorinda@ @et.ufg.br.

** Professor da Faculdade de Agronomia e Medicina Veterinária UnB - Brasília, DF.

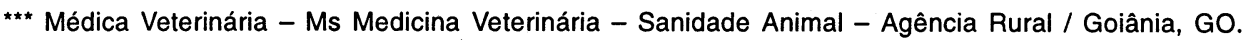

${ }^{\star \star \star \star}$ Estudante Medicina Veterinária Bolsista de iniciação científica.
} 
ver todos os problemas relacionados com a mortalidade, quando a concentração de patógenos no ambiente for alta. Nessas condições, é provável que a adoção do manejo adequado do colostro de forma isolada não seria suficiente para promover um decréscimo na ocorrência das doenças neonatais. Entretanto, quando além do fornecimento de colostro otimizam-se as condições ambientais, é provável que ocorra uma redução no impacto negativo das falhas de transferência de imunidade passiva por ocasião da administração do colostro. Para Ferreira et al. (1996), a baixa resistência dos bezerros às enfermidades e parasitas é um dos fatores de frustração nas explorações leiteiras, especialmente, ao admitir-se que as respostas do animal frente ao agente agressor podem ser influenciadas pela alimentação e aspectos sanitários.

A absorção de imunoglobulinas em bezerros cujos partos foram distócicos tendem a ser menores, possivelmente devido ao efeito depressor da hipóxia que, freqüentemente, reduz a atividade física, retarda a ingestão do colostro e, conseqüentemente, pode ocasionar menor absorção de anticorpos (Santos e Grongnet, 1990).

Bruning-Fann e Kaneene, (1992), estudando possíveis causas de mortalidade em bezerros, encontraram taxas de $1,18 \%$ na Noruega, de $20,20 \%$ na Califórnia, com variação de 0 a $60 \%$ entre as propriedades. Para os autores, as taxas de mortalidade são diversas e são influenciadas por determinados fatores, como as variações climáticas, que geralmente resultam em mortalidade por pneumonia. Santos e Grongnet (1990) admitem uma mortalidade perinatal variando de $5 \%$ a $10 \%$ e as duas primeiras semanas representam a fase crítica da mortalidade, atingindo de $55 \%$ a $70 \%$ do total de perdas. O óbito em mais da metade dos casos é geralmente atribuído às septicemias e diarréias, desencadeadas pelos colibacilos.

Matos (1983) cita que o uso continuado do mesmo bezerreiro pode acarretar menores taxas de crescimento com aumento na incidência de diarréia e na taxa de mortalidade. No Centro Nacional Pesquisa de Gado Leiteiro (CNPGL) constatou-se maior mortalidade de bezerros no período chuvoso que no período seco. Mas o número de óbitos pode diminuir se os bezerros forem mantidos sob sistema de rotação de pastagens limpas e com dosificações periódicas com antihelmínticos.

Bianchin et al. (1994) afirmam que uma das principais causas do aparecimento de doenças nos bezerros do nascimento ao desmame é a cura insuficiente do umbigo dos recémnascidos. Mello et al. (1981) citam que, para evitar tais problemas, logo após o nascimento o umbigo do bezerro deverá ser cortado e desinfectado com tintura de iodo por dois a três dias consecutivos. Para Rizzo e Abreu (1996), a tristeza bovina pode acometer $30 \%$ do rebanho bovino a cada ano e provocar a morte em $80 \%$ dos casos quando estes não são tratados. Nos animais adultos, é possível ocorrer a redução de até $50 \%$ na produção de leite. O controle dos carrapatos e a rotação de pastagens são medidas importantes no controle da doença.

O presente estudo objetivou acompanhar os índices de mortalidade de bezerros, em uma propriedade rural de exploração mista de bovinos, à medida que eram introduzidas mudanças no manejo.

\section{Material e métodos}

O estudo foi realizado no período de 1994 a 1997 em uma propriedade rural de 1000 hectares, na região sudoeste do Estado de Goiás. As pastagens da fazenda na época em que se realizou o experimento eram formadas por piquetes, principalmente de andropogon (Andropogon gayanus) e brachiaria (Brachiaria decumbens). Mantinha-se na propriedade, em média, 650 vacas de graus variados de sangue Zebu/Holandês, utilizando 700 hectares da propriedade nesta atividade. A ordenha era realizada uma vez ao dia no período matutino e os bezerros permaneciam com as mães até as 15 horas, quando eram separados e colocados em piquetes próximos ao curral. No período seco (maio a setembro), após esse horário, eram suplementados nos piquetes com concentrado ${ }^{1}$ e cana picada. No início do estudo, os recém-nascidos eram mantidos nos currais a céu aberto em piso de chão batido por, aproximadamente, uma semana.

A mão-de-obra auxiliar recebeu treinamento na propriedade rural, por meio de cursos teóricos e práticos e visitas a fazendas-modelo.

As principais mudanças adotadas no manejo constaram da formação de um piquete de parição, do acompanhamento do parto, do corte e curativo do umbigo por três dias consecutivos com solução de iodo a $2,25 \%,{ }^{2}$ administração do colostro, distribuída em três a quatro mamadas nas primeiras 24 horas de vida do bezerro; além da formação e utilização de piquetes específicos para bezerros em local seco e em terreno cujo nível era superior ao dos currais. Paralelamente, realizou-se o exame para o diagnóstico da brucelose nas fêmeas em idade reprodutiva. Foram descartados os casos positivos e promoveu-se a vacinação das fêmeas de três a oito meses contra a enfermidade, conforme recomendação de Vanzini (1995).

Para os casos de onfaloflebite, a profilaxia iniciou-se com a utilização de piquetes de parição. Após o parto e os bezerros receberem os primeiros estímulos feitos pela vaca, o umbigo era embebido em solução de iodo por 30 segundos e seccionado com o uso de uma tesoura a aproximadamente dois centímetros da pele. A porção restante era novamente embebida em solução de iodo por aproximadamente 60 segundos (Figueiredo, 1999). Outras medidas profiláticas e/ou curativas com vistas ao controle das enfermidades mais freqüentes na propriedade foram adotadas. Para a onfaloflebite utilizou-se higienização local, ${ }^{3}$ aplicação de pomada repelente e cicatrizante, ${ }^{4}$ além da antibioticoterapia, ${ }^{5}$ nas diarréias, hidratação, ${ }^{6}$ antibioticoterapia ${ }^{7}$ e vacinação de vacas e bezerros; 8 nas pneumonias antibioticoterapia; ${ }^{4}$ nas verminoses deverminação; ${ }^{9}$ no carbúnculo, vacinação ${ }^{10}$ e nas hemoparasitoses, babesicidas ${ }^{11}$ e oxitetraciclina. ${ }^{3}$

\footnotetext{
${ }^{1}$ Concentrado para bezerros Nutroeste - Nutroeste S/A

2 lodophor Fatec - FATEC S.A

3 Álcool lodado

${ }^{4}$ Ungüento Vallê - Vallé Nordeste S/A

5 Terramicina LA - Pfizer S/A

6 Ringer Lactato - Halex Istar

7 Pencivet plus forte - Silva e Araujo Roussel S/A

${ }^{8}$ Vacina cantra Pneumoenterite dos Bezerros - Vallé Nordeste S/a

9 Ripercol - Fort Dodge

10 Polivacina Vallé - Vallé Nordeste S/A

${ }^{11}$ Gasnaseg Sol Inj. Ciba Geyge Quimica S/A
} 
O método escolhido para acompanhar o comportamento das diferentes enfermidades baseou-se em anotações feitas em fichas apropriadas e visitação periódica. O diagnóstico presuntivo das doenças fundamentou-se no histórico, idade de aparecimento dos sinais clínicos e na resposta terapêutica. Os dados referentes à mortalidade dos bezerros foram avaliados por estatística descritiva.

\section{Resultados e discussão}

A mortalidade de bezerros observada no primeiro ano (1994) foi de $18,65 \%$ (61/327). Estes valores foram obtidos por ocasião do primeiro contato com a propriedade, portanto, sem os reflexos da adoção das medidas profiláticas para a melhoria sanitária do rebanho, propostas no presente estudo. No segundo ano (1995), com o início das mudanças introduzidas no manejo, a mortalidade foi de 9,39\% (29/309) e no terceiro (1996) foi de $6,45 \%(22 / 341)$. Já no quarto ano (1997), a mortalidade não ultrapassou o valor de 4,67\% (17/364), conforme mostra a Tabela 1. Apesar da mortalidade ter sido considerada alta no primeiro ano, ainda foi inferior aos $20 \%$ previstos por BruningFann e Kaneene (1992) em função do manejo e do sistema ecológico na qual está inserida a criação. Por outro lado, o índice de mortalidade de $4,67 \%$ encontrado no quarto ano de acompanhamento foi ligeiramente inferior ao intervalo de cinco a $10 \%$ estabelecido como aceitável por Madruga et al. (1984), confirmando a eficiência das medidas adotadas.

O exame realizado para o diagnóstico de brucelose e o descarte de fêmeas positivas pode ter sido uma medida importante para amenizar o nascimento de bezerros fracos que, geral-

Tabela 1 - Distribuição da mortalidade de bezerros por faixas etárias durante os anos de 1994 a 1997 numa fazenda de exploração mista de bovinos no Estado de Goiás

\begin{tabular}{|c|c|c|c|c|c|c|c|c|c|c|c|}
\hline \multirow[t]{2}{*}{ Ano } & \multicolumn{9}{|c|}{ Idade em meses de ocorrência dos óbitos dos bezerros } & \multirow{2}{*}{$\begin{array}{c}\text { Total de } \\
\text { nascimentos } \\
\text { no ano }\end{array}$} & \multirow{2}{*}{$\begin{array}{l}\text { Total de } \\
\text { mortes no } \\
\text { ano }\end{array}$} \\
\hline & $00-01$ & $01-02$ & $02-03$ & 03-04 & $04-05$ & $05-06$ & $06-07$ & $07-08$ & $08-12$ & & \\
\hline 1994 & 11 & 17 & 16 & 6 & 4 & 2 & 2 & 1 & 1 & 327 & 61 \\
\hline 1995 & 8 & 4 & 6 & 4 & 2 & 1 & 0 & 2 & 2 & 309 & 29 \\
\hline 1996 & 3 & 4 & 6 & 4 & 2 & 1 & 1 & 0 & 1 & 341 & 22 \\
\hline 1997 & 5 & 5 & 2 & 2 & 0 & 0 & 1 & 1 & 1 & 364 & 17 \\
\hline Total & 27 & 30 & 30 & 16 & 08 & 04 & 04 & 04 & 05 & 1341 & 129 \\
\hline
\end{tabular}

dos bezerros e, apesar da redução no percentual de mortos nos anos subseqüentes, a tendência de distribuição se manteve, fato que contraria as informações de Santos e Grognenet (1990), de que $70 \%$ da mortalidade em bezerros ocorre especificamente até a segunda semana de vida. Os resultados desse estudo apresentam-se mais próximos dos valores encontrados por Bruning-Fann e Kaneene (1992), os quais mencionam que $20 \%$ dos bezerros desenvolvem diarréia do nascimento ao desmame e a mortalidade pode atingir $10 \%$ nos primeiros 14 dias de vida e $5 \%$ dos 15 aos 90 dias. Quanto à mortalidade por problemas respiratórios, nos primeiros 90 dias é de $7 \%$ e do nascimento ao desmame de $15,4 \%$, segundo os mesmos autores. Outros fatores que podem ser considerados de risco para a mortalidade de bezerros são: os piquetes paridouros (estresse e agentes de doença) e os bezerreiros, já que existem evidências de que o alojamento influencia no nível sérico de IgG nos primeiros 30 dias de vida do recémnascido.

Na Tabela 2, observa-se que as hemoparasitoses, diarréias, pneumonias e onfaloflebites foram as principais causas de morte em bezerros na propriedade em estudo. Para Ribeiro et al. (1983), essas enfermidades são também identificadas em criatórios da região da Zona da Mata de Minas Gerais, mas acrescentam que nessas propriedades a maior ocorrência é de pneumonia seguida das diarréias, hemoparasitoses e onfaloflebite. A alternância na ordem em que as enfermidades provocam a morte dos bezerros, provavelmente, é devida em parte a diferenças climáticas, já que na região onde se realizou esse estudo, mesmo no inverno, a temperatura é amena. No CNPGL constatouse que a maior mortalidade de bezerros ocorreu no período chuvoso e, por esse motivo, Matos (1983) recomenda que os bezerros sejam mantidos em pastagem limpa com rodízios e dosificaçōes periódicas com antihelmínticos. mente, não sobrevivem. Essas medidas fundamentaram-se nas recomendações de Vanzini (1995) e os resultados positivos puderam ser notados já no segundo ano, uma vez que após a sua adoção, não se observaram na propriedade nascimentos de bezerros com os sinais clínicos acima descritos. Além disso, o índice de abortos foi inexpressivo. Os resultados alcançados estão de acordo com as observações de Madruga et al. (1984), que afirmam que as enfermidades possuem características próprias de difusão e apresentam-se sob diferentes formas quanto ao número e intensidade, sendo que os fatores fundamentais no processo de disseminação são as condições ecológicas naturais, o manejo e a raça do animal.

Da mortalidade total observada no primeiro ano (Figura 1), $72,13 \%(44 / 61)$ ocorreram nos três primeiros meses de vida

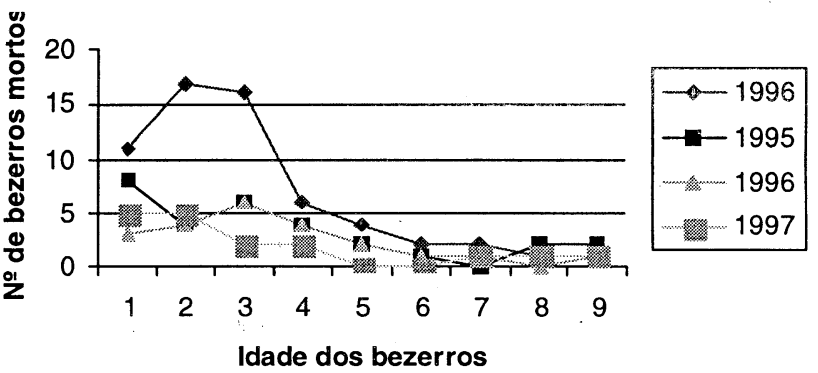

Figura 1 - Distribuição das mortalidades de bezerros por faixa etária nos anos de 1994 a 1997 em uma propriedade rural de exploração mista de bovinos no sudoeste goiano 
Tabela 2 - Distribuição das patologias que provocaram óbitos dos bezerros, de acordo com a faixa etária em uma fazenda de exploração mista de bovinos de 19941997 no Estado de Goiás

\begin{tabular}{|c|c|c|c|c|c|c|c|c|c|c|}
\hline \multirow[t]{2}{*}{ Doenças } & \multicolumn{9}{|c|}{ Idade em meses de ocorrência dos óbitos dos bezerros } & \multirow{2}{*}{$\begin{array}{c}\text { Total de } \\
\text { mortes no } \\
\text { período }\end{array}$} \\
\hline & $00-01$ & $01-02$ & $02-03$ & 03-04 & 04-05 & $05-06$ & $06-07$ & $07-08$ & $08-12$ & \\
\hline Carbú nculo & 00 & 00 & 00 & 00 & 00 & 00 & 00 & 01 & 02 & 03 \\
\hline Desnutrição & 02 & 04 & 04 & 04 & 01 & 00 & 00 & 00 & 00 & 15 \\
\hline Diarréia & 04 & 10 & 06 & 01 & 02 & 00 & 01 & 00 & 00 & 24 \\
\hline Onfaloflebite & 05 & 03 & 01 & 00 & 00 & 01 & 00 & 00 & 00 & 10 \\
\hline Hemoparasitoses & 01 & 07 & 09 & 06 & 00 & 00 & 01 & 01 & 01 & 26 \\
\hline Pneumonia & 01 & 04 & 04 & 02 & 01 & 01 & 01 & 00 & 00 & 14 \\
\hline Verminose & 00 & 01 & 01 & 01 & 04 & 00 & 00 & 01 & 00 & 08 \\
\hline Outros & 14 & 02 & 01 & 02 & 00 & 02 & 01 & 01 & 02 & 25 \\
\hline Total & 27 & 31 & 26 & 16 & 08 & 04 & 04 & 04 & 05 & 125 \\
\hline
\end{tabular}

As mortes por diarréia ocorreram em $19,2 \%$ dos bezerros (24/125), índice considerado elevado, mas que reforça os achados de Ribeiro et al. (1983), que descrevem a diarréia como a doença mais freqüente, observada em $66 \%$ das propriedades. Esses achados também encontram respaldo no estudo realizado por Viana et al. (1987), que avaliou rebanhos de aptidão leiteira no município de Sete Lagoas (MG) e detectou a diarréia dos bezerros como a doença mais im-

Ao iniciar o estudo, durante o ano de 1994, existiam fortes indicios de que a falta de higiene nos currais e o excesso de umidade, observados nos locais em que os recém-nascidos permaneciam durante a primeira semana de vida, bem como a cura inadequada do umbigo, contribuíam para aumentar a ocorrência de óbitos, sobretudo devido às diarréias, pneumonias e onfaloflebites. Para Matos (1983), a higiene deficiente, o excesso de umidade e a produção de amônia são fatores que podem contribuir para o aumento na incidência de problemas respiratórios em recém-nascidos criados em bezerreiros tradicionais e sugere a criação de bezerros em piquetes, por ser a forma mais econômica e sanitariamente eficiente de criação. Na propriedade estudada optou-se pelo uso de piquetes localizados em local seco e em terreno cujo nível fosse superior ao dos currais, a fim de diminuir a contaminação, decorrente da movimentação de efluentes que ocorre nos desníveis dos terrenos por ação da gravidade. Para Barros (1969), concorre para os baixos índices de produtividade dos rebanhos a carência de tecnologias para o nosso meio que, freqüentemente, são agravadas pelos aspectos socioeconômicos.

Do total de óbitos, $20,8 \%$ (26/125) foram atribuídos às hemoparasitoses, sendo esta enfermidade a que mais provocou a morte de bezerros na propriedade amostrada, contrariando o inquérito realizado por Ribeiro et al. (1983), no qual conclui-se que as hemoparasitoses podem levar à morte menor percentagem de bezerros. Já em levantamentos feito por Viana et al. (1987), as hemoparasitoses foram a segunda doença de importância na criação de bovinos e, para Rizzo e Abreu (1996), elas atingem alto percentual de animais do rebanho nacional, com uma mortalidade de até $80 \%$ em bezerros que não são devidamente tratados. portante. Para Madruga et al. (1984), a incidência e a etiologia das doenças dos bezerros são variáveis de região para região ou, até mesmo, de fazenda para fazenda, e os principais processos patológicos relacionados com a morte desses animais são as diarréias, a onfaloflebite, as hemoparasitoses e as pneumonias (Figura 2).

A mortalidade por carbúnculo (Tabela 2) foi baixa (3/125) e ocorreu em bezerros com idade próxima a um ano de vida, 0 que está de acordo com as citações de Bier (1999).

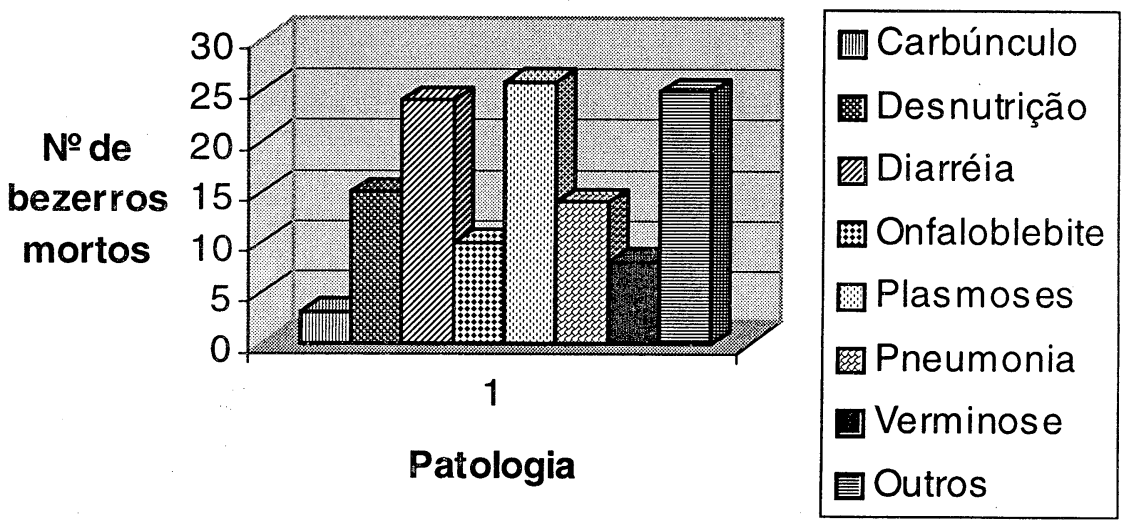

Figura 2 - Principais patologias que foram causa de mortalidade de bezerros entre os anos de 1994 e 1997 em uma propriedade de exploração mista de bovinos no sudoeste goiano.

Tabela 3 - Mortalidade dos bezerros distribuídas por doença ao longo dos meses do ano, em uma fazenda de exploração mista de bovinos no Estado de Goiás de 1994 a 1997

\begin{tabular}{|c|c|c|c|c|c|c|c|c|c|c|c|c|c|}
\hline \multirow[t]{2}{*}{ Doenças } & \multicolumn{12}{|c|}{ Idade em meses de ocorrência dos óbitos dos bezerros } & \multirow{2}{*}{$\begin{array}{l}\text { Total de } \\
\text { mortes no } \\
\text { período }\end{array}$} \\
\hline & Jan. & $\mathrm{Fev}$ & Mar & $\mathrm{Abr}$ & Maio & Jun. & Jul & $\mathrm{Ag}_{0}$ & Set & Out & Nov & Dez & \\
\hline Carbúnculo & 00 & 00 & 00 & 00 & 00 & 00 & 00 & 00 & 00 & 00 & 02 & 01 & 03 \\
\hline Desnutrição & 00 & 00 & 01 & 01 & 00 & 02 & 02 & 05 & 02 & 01 & 00 & 00 & 14 \\
\hline Diarréia & 05 & 05 & 01 & 00 & 00 & 00 & 00 & 00 & 01 & 03 & 03 & 06 & 24 \\
\hline Onfaloflebite & 02 & 00 & 00 & 00 & 00 & 00 & 00 & 01 & 01 & 02 & 01 & 01 & 08 \\
\hline Hemoparasitose & 01 & 00 & 00 & 01 & 03 & 04 & 04 & 03 & 01 & 04 & 01 & 04 & 26 \\
\hline Pneumonia & 00 & 00 & 01 & 02 & 03 & 03 & 03 & 02 & 01 & 00 & 00 & 00 & 15 \\
\hline Verminose & 00 & 00 & 00 & 00 & 01 & 01 & 01 & 02 & 01 & 02 & 00 & 00 & 08 \\
\hline Outros & 02 & 03 & 00 & 00 & 04 & 01 & 02 & 02 & 02 & 05 & 03 & 02 & 27 \\
\hline Total & 10 & 08 & 03 & 04 & 11 & 11 & 12 & 15 & 09 & 17 & 10 & 14 & 125 \\
\hline
\end{tabular}


Houve uma tendência de se manter uma distribuição equivalente das mortes totais de bezerros, em todos o meses do ano, exceto de março a abril, talvez por que nesse período existissem menos bezerros na faixa de zero a três meses (Tabela 3). Durante o período de suplementação, o índice de mortalidade também não variou muito, mas o aumento verificado de outubro a dezembro pode ser atribuído à precipitação pluviométrica que foi alta na região, dificultando em parte a manutenção higiênica dos locais onde os bezerros permaneciam. Soma-se a isso o fato desse período, geralmente, coincidir com o pico de produção de leite de animais a pasto e o fato do manejo adotado (vaca com bezerro) não controlar a ingestão de leite que, quando em excesso, pode ter contribuído para os casos de diarréia.

A mortalidade por diarréia teve como época de maior ocorrência o período chuvoso, que na região estudada vai de setembro a março (Figura 3). Essa observação mostra que as condições ambientais também podem ter influenciado na ocorrência da enfermidade na propriedade estudada, mesmo depois das mudanças no manejo. Matos (1983) descreve

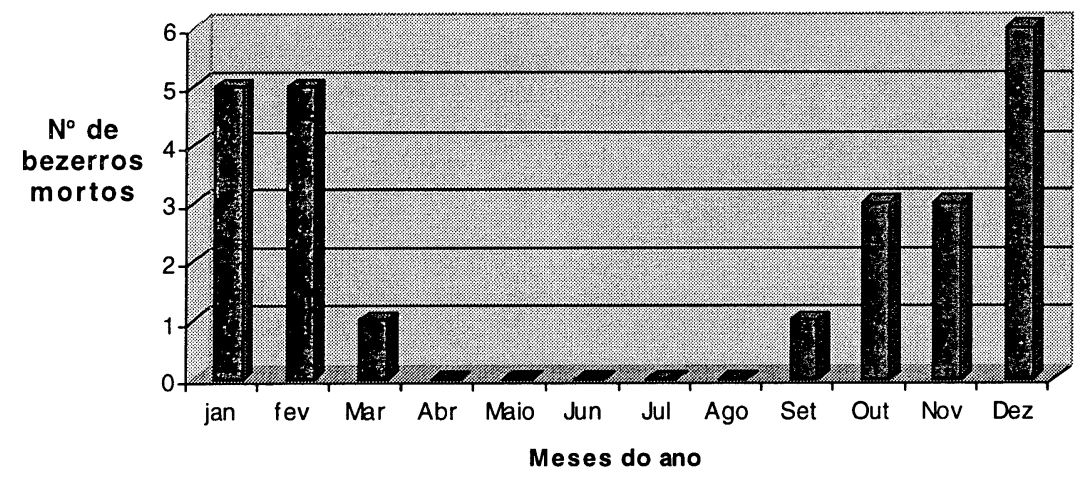

Figura 3 - Distribuição da mortalidade de bezerros por diarréia nos meses de janeiro a dezembro de 1994 a 1997 em uma propriedade rural de exploração mista de bovinos no sudoeste goiano

que a criação de bezerros fora de bezerreiros fechados é mais econômica e que os fatores relacionados com o ambiente podem acentuar outros problemas que levam à mortalidade.

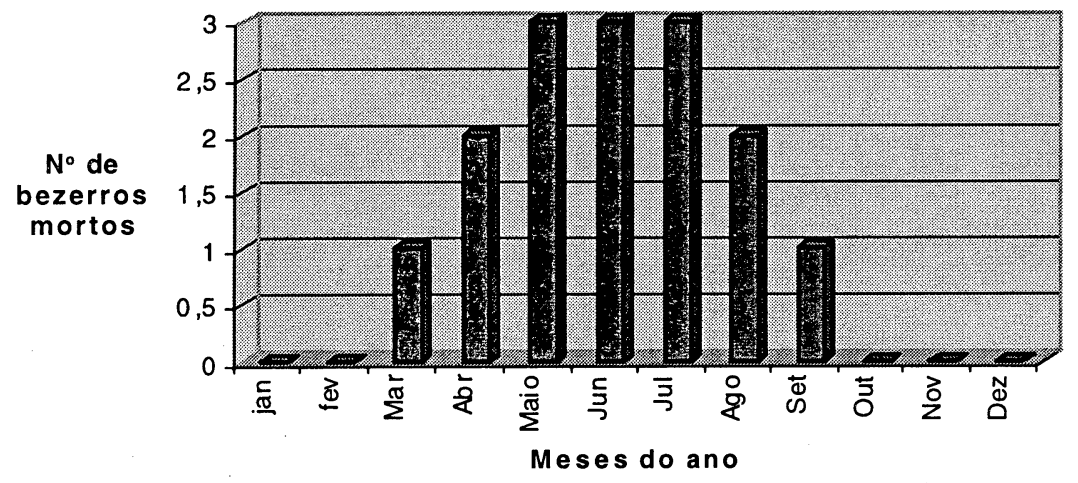

Figura 4 - Distribuição da mortalidade de bezerros por pneumonia nos meses de janeiro a dezembro dos anos de 1994 a 1997 em uma fazenda de exploração mista de bovinos no sudoeste goiano
O autor menciona também que o aumento nos casos de diarréia no período chuvoso é freqüente, mesmo nos criatórios com alimentação a pasto e bezerro ao pé.

Apesar da pneumonia não ser a enfermidade que mais provocou óbitos no estudo aqui realizado (14/125), ela esteve presente, principalmente entre os meses de maio a agosto, coincidindo com o período de baixas temperaturas na região do sudoeste goiano (Tabela 2 e Figura 4). Esses achados estão de acordo com os de Ribeiro et al. (1983), os quais relacionam as pneumonias como as principais causas de morte de bezerros, na região da Zona da Mata em Minas Gerais, durante o inverno.

A onfaloflebite, apesar de descrita como uma doença de baixa letalidade, neste estudo foi a quinta causa de morte dos bezerros (10/125). Mesmo assim, ficou evidente que o proprietário rural e/ou seus auxiliares não relacionam tal afecção com o desenvolvimento de outras enfermidades como diarréias, artrites, tétano, dentre outras doenças que ocorrem na propriedade. Considerou-se como um obstáculo na implementação de medidas profiláticas, o despreparo do pessoal envolvido na lida da propriedade e o fato de não aceitar que a onfaloflebite, mesmo não causando rotineiramente a morte do animal, pode influenciar negativamente no desenvolvimento dos bezerros. Ribeiro et al. (1983b) acrescentam que muitos casos de onfaloflebite podem ser causados por doenças como brucelose e leptospirose. A grande ocorrência aqui observada, sobretudo no início do período de avaliação, reforça o fato de que os conhecimentos já existentes sobre a cura do umbigo nem sempre estão ao alcance do homem rural. Bianchin et al. (1994) relatam que os criadores de gado de corte geralmente não fazem adequadamente a cura do umbigo alegando dificuldades de manejo e não por desconhecer a importância dessa medida profilática, como observado em certos criatórios de raças mistas ou de aptidão leiteira.

A absorção das imunoglobulinas colostrais pelos bezerros neonatos termina 24 a 48 horas após o nascimento, conforme relata Santos e Grongnet (1990). Neste estudo, o preenchimento desta lacuna parece ter ocorrido com a adoção de assistência ao parto e o fornecimento imediato do colostro. Para Ribeiro et al. (1983a), mesmo em um rebanho com um bom manejo de colostro até $37,7 \%$ dos bezerros podem sofrer de hipogamaglubulinemia, por características individuais. Talvez por este motivo a redução gradativa no índice de óbitos nos animais recém-nascidos possa estar relacionada também à melhora das condições higiênico-sanitárias de ordem geral, diminuindo o desafio dos bezerros aos patógenos.

Neste estudo ficou evidenciado que a adoção de medidas profiláticas é imperiosa e pode reduzir os índices de mortalidade em bezerros. A diferença em percentuais de mortalida- 
de observados entre a avaliação inicial feita em 1994 e a final realizada em 1997, indica de forma positiva a eficiência dos procedimentos adotados. Todavia, a queda escalonada dos percentuais de mortalidade dos bezerros ocorrida ano a ano deve-se, provavelmente, entre outros fatores, à mão-de-obra auxiliar, que nem sempre se manteve por muito tempo na propriedade, além da dificuldade de assimilação dos ensinamentos. Uma outra limitação foi que as mudanças no manejo, nos hábitos higiênicos, na alimentação e no controle sanitário, também foram gradativos; caso contrário, poderiam gerar forte impacto sobre os custos.

\section{Referências}

BIANCHIN, I., CORRÊA, E.S., GOMES, A., HONER, M.R., CURYO, J,B.E. Uso de ivermectin na prevenção de míiases umbelicais em bezerros de corte criados extensivamente. EMBRAPA-CNPGC. Campo Grande. Comunicado Técnico. 2. ed. 6p. 1994.

BIER, J. Doenças infecciosas em animais domésticos. Rocca, São Paulo. v.1, 1999.

BRUNING-FANN, C., KANEENE, J.B. Environmental and Managemente Risk factors Associated with Morbidity and Mortality in Perinatal and Pre-weaning Calves: a Review fron na Epidemiological Perspective. Vet. Bull. v. 62, n. 5, p. 399-413, 1992.

FERREIRA, M.A., CASTRO, A.C.G., SILVA, J.F.C., CAMPOS, J.M.S., CECOM, P.R. Sistemas de aleitamento de bezerros. 2. Desempenho dos bezerros. Rev. Bras. Zoot. Viçosa. v. 25, n. 4, p. 729-740, 1996.

FIGUEIREDO, L.J.C. Onfaloflebites de bezerros. EDUBRA. Salvador. 1999.

MADRUGA, C.R., GOMES, R., SCHENK, M.A.M., KESSELER, R.H., GRATÃO, G., GALES, M.E., SCHENK, J.A.P., ANDREASI, M., BIANCHIN, I., MIGUITA, M. Etiologia de algumas doenças de bezerros de corte no Estado de Mato Grosso do Sul. EMBRAPA-CNPGC. Campo Grande. Circular Técnica, n. 13, fev. 1984. 27p.

MATOS, L.L. Criação de bezerros a pasto. EMBRAPA-CNPGL. Coronel Pacheco. Circular técnica. n. 19, set. 1983.

\section{Conclusões}

As hemoparasitoses, diarréias e pneumonias foram as principais causas de morte dos bezerros na propriedade avaliada.

A maior concentração de óbitos ocorreu até 90 dias de vida dos bezerros.

As mudanças adotadas de forma gradativa no manejo levaram a redução nos índices de mortalidade observados ao início e ao final.

A mão-de-obra auxiliar respondeu satisfatoriamente aos investimentos feitos com vistas à capacitação profissional.

MELLO, R.P., MOREIRA, H,A., OLIVEIRA, F.M. // dia de campo do CNPGL. EMBRAPA-CNPGL. Coronel Pacheco, 72 p. il. 1981.

RIBEIRO, M.F.B., SALCEDO, J.H.P., BELÉM P.A. d., FARIA, J.E. Hipogamaglobulinemia em bezerros. Arq. Bras. Med. Vet. Zoot. v. 35, n. 4, p. 537-546, 1983a.

RIBEIRO, M.F.B., SALCEDO, J.H.P., SANTOS, J.L., FARIA, J.E. Inquérito de Opinião da Zona da Mata do Estado de Minas Gerais: I. Alguns Fatores Associados com Mortalidade de Bezerros. Arq. Bras. Med. Vet. Zoot.. v. 35, n. 4, p. 547-556. 1983b.

RIZZO, İ., ABREU, L.H. Como combater a tristeza dos animais com manejo. Produtiva. v.1, n. 2, p. 44-45, 1996.

SANTOS, G.T., GRONGNET, J.F. Transmissão da imunidade passiva colostral em ruminantes. Gado Holandês. v.56, n. 178, p. 17-30, set. 1990.

VANZINI, V. Las pruebas sorológicas utilizadas para el control de la brucelosis bovina In: INTA. Estrategias para el control de la brucelosis de los bovinos con énfasis en establecimentos con alta prevalencia. INTA-Estação experimental de agropecuária Rafaela. Oct 1995.20p.

VIANA, F.C., CRUZ, F.E.R., LAENDER, F.C., VALENTE, J.O., CONTRERAS, R. L., SILVA FILHO, M.P. Diagnóstico da situação de Produção Bovina de Leite do Município de Sete Lagoas - MG. Arq. Bras. Med. Vet. Zoot. v. 39, n. 5, p. 699-717, 1987. 